\title{
Primary and secondary dental care: the nature of the interface
}

\author{
A. J. Morris' and F. J. T. Burke 2
}

\begin{abstract}
Specialist dental services are scarce resources and are often oversubscribed. A key element is how these services relate to their referral base, in other words the interface between primary and secondary dental care. Dentistry has several unique qualities when compared with medicine and the nature of the interface between primary and secondary dental care is consequently very different to the medical interface, whilst apparently sharing common features. This paper examines the nature of that interface, the drivers for patient flow between services and outlines the properties of an ideal interface. This model can then be used as a way of describing some of the problems facing specialist dental services and of assessing any proposed solutions.
\end{abstract}

$\mathrm{D}$ entistry is essentially a primary care discipline insofar as the vast majority of patient care takes place in community settings, is restricted to simple procedures and is provided by 'generalists' who in the main hold, or aspire to hold, a long-term relationship with their patients. ${ }^{1}$ In medicine, a key aspect of recent health policy has been to drive the provision of a greater proportion of care in community settings by generalists and thus reduce the referral rate to secondary care. This policy has had major implications for medicine in the last decade $^{2,3}$ and is a key element in the new NHS Plan. ${ }^{4}$

In dentistry most care is provided by generalists and patients are rarely referred to specialists, though referral rates are reported to have risen greatly in recent years and are likely to continue to do so. Thus, as in medicine, secondary dental care providers and commissioners experience problems in managing demand. Dentistry differs from medicine, however, in that a larger propor-

\footnotetext{
${ }^{1}$ Lecturer in Dental Public Health ${ }^{2}$ Professor of

Primary Dental Care

${ }^{*}$ Correspondence to: John Morris, School of Dentistry, The University of Birmingham, St Chad's Queensway, Birmingham B4 6NN

email:a.j.morris@bham.ac.uk

REFEREED PAPER

Received 03.04.01; Accepted 20.07.01

(C) British Dental Journal 2001; 191: 660-664
}

tion of care is provided outside hospitals (where it often attracts patient charges) and secondary care is more likely to be on an outpatient basis. In addition, liaison with secondary care forms substantially less of a general dental practitioner's (GDP's) working day than it does for a general medical practitioner. The routine work of many GDPs includes items of care which has at times been regarded as spe- cialised, for instance orthodontics and endodontics. Some forms of care are often provided by academics with honorary NHS contracts working within dental hospitals; in some cases there might only be a single consultant in a particular specialty for a whole NHS region. Lastly, a significant amount of secondary dental care is provided by non-consultants outside of hospi-

\section{In brief \\ - This paper summarises the published work describing how primary and secondary dental care relate to each other (interface) \\ - A model describing the properties of an ideal interface is suggested \\ - This model can be used to help categorise perceived problems with the interface and suggested solutions}

tals and this may rise further with the development of specialised services with Dental Bodies Corporate (DBCs). The interface between primary (PDC) and secondary dental care (SDC) therefore, whilst sharing some common features with medicine, is likely to be different because of the differing nature of both primary and secondary dental care from their medical counterparts.

This paper examines the nature of the interface and the drivers for patient flow between services as a precursor to discussing how the interface might be improved.

\section{The features of the interface}

The interface between primary and secondary dental care displays three key features; interdependence, integration and complexity.

\section{Interdependence}

Primary and secondary care providers are dependent upon each other. On the one hand the PDC provider needs somewhere to refer patients who need treatment outside his or her knowledge and competence; and may need support for patients whose treatment might be provided within primary care but for whom specialist advice is needed to facilitate this. SDC providers are reliant upon PDC as the main source of their referrals (which in turn generate research and training material for undergraduate and postgraduate students) and need an outlet for the return of completed cases for routine maintenance care. Changes on either side of the equation or shifts in the location of the interface can affect both sides and a wide range of factors might affect the flow of patients between PDC and SDC (Fig. 1) and between different SDC providers.

Integration - co-operation, communications and coordination Co-operation and good communications are essential for a successful interface. Both sides need to be clear about what the other is requesting or proposing, particularly when the treatment requires them to 


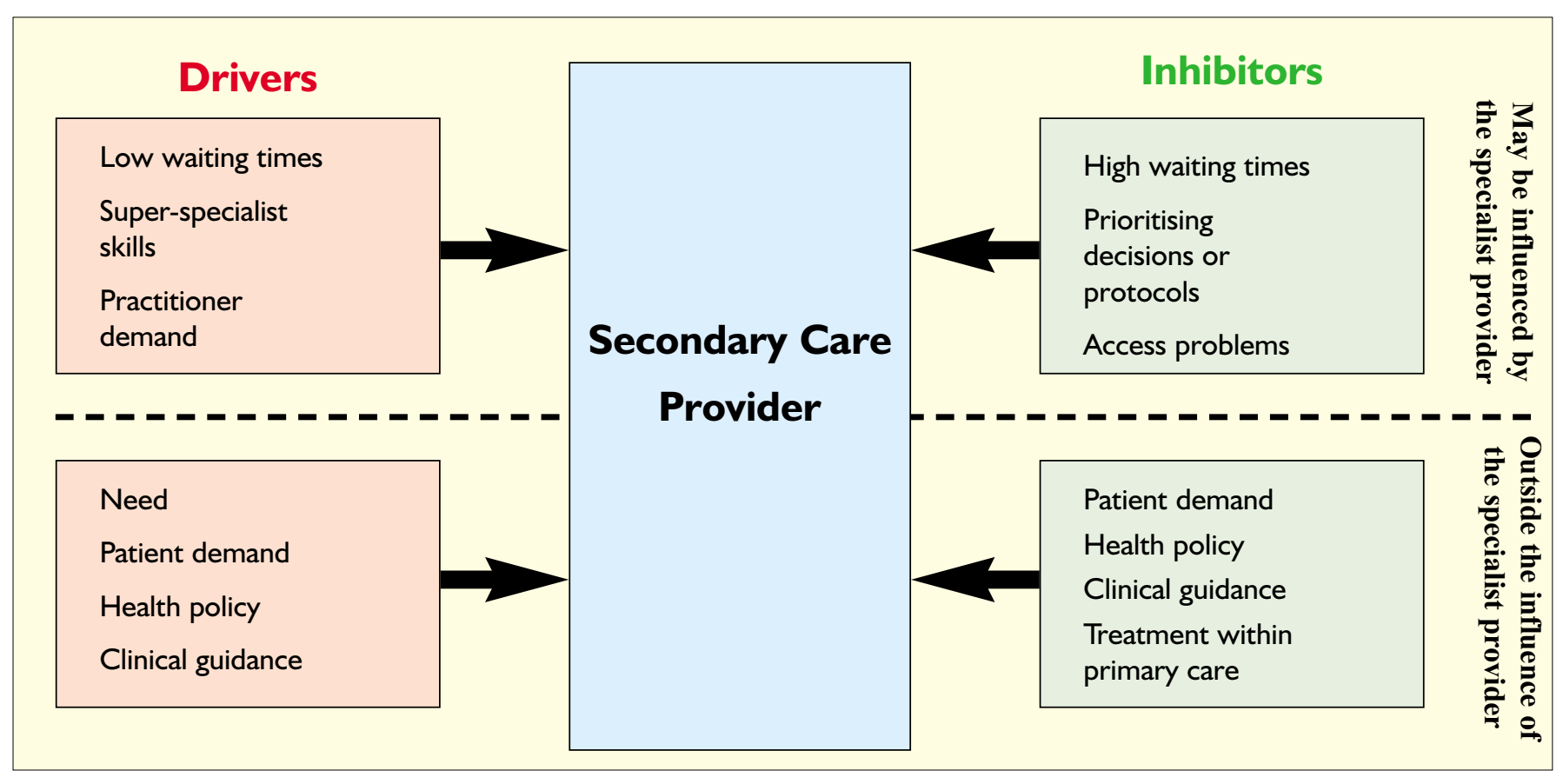

Fig. I The drivers and inhibitors for referral to secondary dental care

co-ordinate their efforts. In their guidance for practitioners referring to consultant orthodontic services, Ferguson, Langford and Davenport ${ }^{5}$ recommended that practitioners bear in mind the pressures under which such services operate and consider a number of factors when making a referral. Some services have introduced referral guidelines to assist decision-making by referring practitioners, though there are few completed studies evaluating their effect. ${ }^{6}$

Despite the influx of IT into dental practice, letters are still the main means of communication. In a survey of dental consultants, ${ }^{7}$ a number of features of an ideal referral letter were identified, with little variation between specialties including a clear statement as to why a referral is being made, whether or not malignant disease is suspected and an indication of the urgency of the referral. However, the advice is not all one-sided; in a survey of 268 general dental practitioners and 13 orthodontic consultants $^{8}$ GDPs had several points to make about what they valued in reply letters from consultants following the initial patient visit. Apart from details allowing patient identification, the contents scoring highest were a proposed treatment plan, the date of the visit and feedback on the appropriateness of referral.

The coordination of primary and secondary care services is less amenable to guidance and probably presents the greatest challenge. In a study comparing referrals to specialist orthodontic practitioners with a consultant-led unit ${ }^{9}$ it was found that referring dentists did not discriminate between the different services, the two specialist groups in effect competing rather than complementing each other.

\section{Complexity}

Like its medical counterpart, the dental interface is complex, though it can sometimes appear to be composed of simple issues, particularly when waiting list problems are being discussed. Secondary care services are subject to a range of influences driving the referral rate and have a number of options for managing increased referrals. How they choose to manage such pressures has impacts both on other services and on the forces driving referral. It is worth remembering that, as in medicine ${ }^{10}$ there are likely to be differing perceptions as to which professional groups are able to con- trol the process. In addition, different parts of the country will find different local solutions to their problems; what apparently works in one area will not necessarily work in another. The question then is what factors act as catalysts and barriers for referral? These are likely to be multiple (Fig. 1), some acting in the short term and capable of being manipulated by stakeholders, others tending to act in the longer term.

\section{Drivers for referral}

Population need and demand

If the role of healthcare services is to meet need, then changes in the levels of some conditions will obviously be a significant driver for referrals to secondary care. National epidemiological surveys of children ${ }^{11,12}$ demonstrate falling dental caries experience and the latest adult dental health study ${ }^{13}$ confirms a continued reduction in the prevalence of total tooth loss, though improvements in tooth retention in middle aged and older adults are mainly in terms of restored rather than sound untreated teeth. From this we might suppose that referrals to specialists should have reduced over the last twenty to thirty years. The relationship 
between population changes in disease experience and the demand for specialised services is complex however; falling disease experience often comes alongside raised public expectations for oral health and demand for a wider range of problems to be dealt with. For instance, falling child caries levels have paralleled increased demand for orthodontics. Public demand may be influenced by other factors besides need, such as information on services available, the media, personal contact with people who have experienced specialist care and of course dentists themselves. Changes in disease levels therefore may be associated with both positive and negative influences on referral rates, acting both through the opportunities for referral presented by the presence of disease and through changing patient attitudes which are both a factor in and a consequence of changing disease levels.

Primary dental care practitioner as promoter and gatekeeper

The key factor in determining referral is almost certainly the primary care practitioner in their 'gatekeeper' or filtering role. PDC practitioners stimulate demand in terms of identifying patients who would benefit from specialised care, in promoting referral to the patient, and have a key role in managing inappropriate demand. Perhaps surprisingly, despite the differences between primary and secondary dental care in terms of direct costs to patients, there is little evidence that this is a major factor in referral, at least not for minor oral surgery. ${ }^{14}$

PDC practitioners may be subject to a number of influences when making referral, including past experience and training and their attitude towards certain conditions. In addition there will be straightforward business decisions based around the perceived financial viability of treating certain conditions and the likelihood of a successful outcome. In a qualitative study involving general dental practitioners and patients ${ }^{15}$ a variety of views about how they related to specialist services were elicited. Most recognised the services as scarce resources which should not be abused and reported taking steps to avoid inappropri- ate referrals such as not referring people for orthodontic treatment when they demonstrated poor self-care. A minority reported referring patients for treatment, not because they were unable to carry out that treatment but because that treatment was not a 'practice builder'. Some respondents thought that rising clinical standards were a factor in driving up referrals. Changes in guidance related to general anaesthesia were a common example given but some also reported that they felt discouraged from undertaking orthodontic treatment because of increased scrutiny from the
Dental Reference Service, a viewpoint which was agreed with by three quarters of respondents in the postal questionnaire part of the study. The predictability of the envisaged treatment was also regarded as a factor; less predictable and/or protracted treatment being less attractive.

In the case of general anaesthesia for dental procedures there is now a clear directive from the $\mathrm{CMO} / \mathrm{CDO}$ report on general anaesthesia and sedation ${ }^{16,17}$ which will have the effect of moving residual general anaesthetic provision into hospitals. Lastly, primary dental care practitioners

\section{Factors associated with:}

\section{Higher referral rate}

High levels of need amongst patients under care

Older practitioner

Postgraduate education (improved surveillance)

Reduced desire or ability to be selective

\section{Remuneration system (rewards referral)}

Clinical standards or external scrutiny driving referral to specialists

Management directives to refer certain categories of patient

Short distance from specialist provider

No advanced clinical skills

\section{Lower referral rate}

Low levels of need amongst patients under care

Younger practitioner

Postgraduate education (improved selection)

Reduced ability or desire to screen patients

Remuneration system (rewards treatment)

Clinical support for dentists wishing to carry out advanced care

Management directives restricting dentists' right to refer

Long distance from specialist provider

Advanced clinical skills 
may be increasingly guided towards referral through clinical governance mechanisms or advice from indemnity organisations.

\section{Differences between primary dental care (PDC) practitioners}

Variations in referral rates between different practitioners, even when expressed as a function of the number of patients under their care, are difficult to interpret. On one hand a high referring practitioner may be inappropriately referring cases which are well within their abilities. On the other hand a low referral rate might be the result of a poor ability to identify patients who would benefit from specialist care. One obvious explanation for variations amongst dentists might be different levels of need amongst their patients, but there are other factors.

In a study of 400 GDPs in Manchester ${ }^{18}$ it was found that, not surprisingly, the anticipated difficulty of the planned procedure was the most common reason for referral. There was, however, a wide variation in referral rate between different practitioners; $29 \%$ said that a preference not to carry out surgical procedures was a factor in making referrals and a similar proportion cited lack of appropriate facilities or staff as a factor. More surprisingly, those who had received postgraduate training were not only found to carry out more procedures in their own practices but were also more likely to refer patients, suggesting that practitioner education may exert both positive and negative influences on referral rates.

A survey of dentists operating in a health maintenance plan referring to endodontic specialists in the USA ${ }^{19}$ found that older, more experienced dentists were more likely to refer. Managed care organisations (MCOs) in the USA have placed restrictions upon referral to specialists, presumably as a way to control costs, insisting that the generalist carry out treatment, particularly when periodontal treatment is proposed. ${ }^{20}$

Whilst this is unlikely to be a factor with new DBCs providing routine care in the UK, the reverse might occur where dentists are encouraged to refer in certain circumstances, either as a way of limiting the treatment provided by the dentist or as a form of risk management.

\begin{tabular}{|c|c|}
\hline Table 2 & $\begin{array}{l}\text { s of the ideal interface between primary and } \\
\text { iry care }\end{array}$ \\
\hline Ideal Quality & Features \\
\hline Equity & $\begin{array}{l}\text { All appropriate cases in the population are referred for } \\
\text { specialist care } \\
\text { No barriers to receiving specialist care once referred }\end{array}$ \\
\hline Seamless care & $\begin{array}{l}\text { All required treatment is available and accessible in } \\
\text { either primary or secondary care services } \\
\text { Transition between primary and secondary care is } \\
\text { easily arranged }\end{array}$ \\
\hline $\begin{array}{l}\text { Efficiency } \\
\text { \& Effectiveness }\end{array}$ & $\begin{array}{l}\text { All referrals are appropriate and timely, primary care } \\
\text { mechanisms for filtering are foolproof } \\
\text { No inappropriate capture and retention of patients by } \\
\text { secondary services, patients are referred back } \\
\text { once specialist care is complete } \\
\text { Routine care by PDC practitioner continues as } \\
\text { appropriate during lengthy courses of specialist care }\end{array}$ \\
\hline
\end{tabular}

It has been suggested that distance from the specialist may be a factor, ${ }^{21}$ dentists close to a specialist centre being more likely to refer. Whether this is entirely a practitioner factor or one modified by patient factors is unclear.

Lastly, and perhaps most obviously, the development of advanced clinical skills within primary care may well be a factor in reducing referrals; a survey of oral surgery provision in England and Wales between 1984 and $1991^{22}$ suggested that an increase in oral surgery provision in the NHS General Dental Services might be linked to improved skills and diagnostic equipment. Practitioner factors reportedly associated with referral are summarised in Table 1.

The role of the specialised service as a factor in referral rates

It is apparent from a number of studies that factors relating to the specialised services themselves exert an influence on decisions to refer. In the study by Coulthard et. al., ${ }^{18}$ GDPs reported several factors influencing referral including: length of waiting list $(57 \%)$, personal contact with a surgeon (56\%) and the ease of access (52\%). Thus, an NHS trust with waiting list problems which appoints an additional specialist with associated support might find that any net reductions in the number of patients waiting are less than the extra number of patients seen and treated unless further mechanisms are brought to bear. A simple analogy would be what happens when attempts are made to solve traffic congestion by building new roads. This effect might be magnified by the new specialist undertaking purposive or accidental selfpromotion to PDC practitioners, for instance by giving postgraduate lectures.

The consequences of developing local links and 'being known' are potentially 
great as seen in a study of implant referral patterns. ${ }^{23}$ Almost certainly the location of specialised care is a major factor; dentists working near a dental hospital will have fewer problems in referring their patients than those in locations at a considerable distance. The situation is made worse if treatment is likely to require multiple visits.

\section{Individual patient factors in driving referral}

Little is published on patient factors in referral for specialised dental care. Fear of hospitals, low expectations and communication problems have been cited as barriers to referral for medical conditions ${ }^{24}$ and the same factors might well be active in dentistry. It is also possible that, as in medicine, some patients are more aware of the opportunities presented by specialist dental care and demand referral by their dentist. Certainly there is some evidence of inequality of uptake of specialist care ${ }^{25}$ but the extent of the problem and the underlying reasons are unclear. In the study by Bradnock and Waplington $^{15}$ a number of patient factors relating to referral were identified including a high degree of trust amongst regular attenders in their own dentist and a consequently strong preference to have all procedures carried out by them. This feeling probably varies depending on the planned procedure. For example some patients might, on the basis of lay experience, expect to be referred to hospital for wisdom tooth removal.

\section{The ideal interface}

The ideal qualities of the interface between PDC and SDC can be summarised under the headings of equity, seamless care, and efficiency and effectiveness (Table 2). An equitable interface could be defined as one where all appropriate cases are referred regardless of other factors and there are no barriers to receiving specialist care following referral. A seamless service could be defined as one where any treatment not available in PDC is available and accessible in SDC and transition between different providers is easily arranged. A completely efficient and effective interface is one where all referrals are appropriate and happen at the right time, patients are referred back to PDC once 'specialised' treatment is completed, they continue to see their PDC practitioner during lengthy courses of treatment within SDC and referral and discharge to maintenance processes are infallible. Obviously, the ideal situation does not exist in UK health services but keeping this framework in mind can assist with describing problems with the interface and their relative importance. In the next paper, we will look at those problems and some suggested solutions.

1 Morris A J, White D A, Bradnock G. Primary care: time to revise the definition? Prim Dent Care 2000; 7: 93-96.

2 Evans D. A stakeholder analysis of developments at the primary and secondary care interface. Br J of Gen Pract 1996; 46: 675-677.

3 Hausman D D, Le Grand J. Incentives and health policy: primary and secondary care in the British National Health Service. Soc Sci Med 1999; 49: 1299-1307.

4 Department of Health. The NHS Plan: A plan for investment, a plan for reform.Cm 4818-I. London: The Stationary Office, 2000.

5 Ferguson J W, Langford J W, Davenport P J. Making the best use of consultant orthodontic services, part 1: determining which patients require referral. Dent Update 1997; 24: 15-17.

6 Dowie R. A review of research in the United Kingdom to evaluate the implementation of clinical guidelines in general practice. Fam Pract 1998; 15: 462-470.

7 McAndrew R, Potts A J C, McAndrew M, Adam S. Opinions of dental consultants on the standard of referral letters in dentistry. Br Dent J 1997; 182: 22-25.

8 Hammond M, Evans D R, Rock W P. A study of letters between general dental practitioners and consultant orthodontists. Br Dent J 1996; 180: 259-263.

9 Langford J W, Ferguson J W. A comparison of consecutive orthodontic referrals seen by a consultant unit and specialist orthodontic practitioners. Br J Orthod 1995; 22: 347-353.

10 Somerset M, Faulkner A, Shaw A, Dunn L, Sharp D J. Obstacles on the path to a primary-care led National Health Services; complexities of outpatient care. Soc Sci Med 1999; 48: 213-215.

11 O'Brien M. Children's dental health in the United Kingdom 1993 London: HMSO 1994.

12 Pitts N B, Evans D J, Nugent Z J. The dental caries experience of 14-year-old children in the United Kingdom. Surveys coordinated by the British Association for the Study of Community Dentistry in 1998/99. Community Dent Health 2000; 17: 48-53.

13 Kelley M, Steele J, Nuttall N, et al. (Walker A. and Cooper I. ed) Adult Dental Health Survey: Oral Health in the United Kingdom 1998. London: The Stationary Office, 2000.

14 Clark S. General dental practitioner referral patterns for minor oral surgery. Prim Dent Care 1995; 2: 11-14.

15 Bradnock G, Waplington J. Commissioning primary dental care: the perceptions of the practitioners and the public. School of Dentistry. The University of Birmingham, 1997.

16 Department of Health. A conscious decision: a review of the use of general anaesthesia and conscious sedation in primary dental care. London, 2000.

17 Department of Health. General Anaesthesia for Dental Treatment. Letter to dental profession 15/2/01 (Helen Robinson).

18 Coulthard P, Kaxakou I, Koron R, Worthington $\mathrm{H}$ V. Referral patterns and the referral system for oral surgery care. Part 1: general dental practitioner referral patterns. Br Dent J2000; 188: 142-145.

19 Caplan D J, Reams G, Weintraub J A. Recommendations for endodontic referral among practitioners in a dental HMO. J Endod 1999; 25: 369-375.

20 Bierig J R. Legal considerations for periodontists in dealing with managed care organisations. J Periodontol 1998; 69: 254-260.

21 Linden G J, Stevenson M, Burke F J T. Variation in periodontal referral in two regions in the UK. J Clin Periodontol 1999; 26: 590-595.

22 Thomas D, Walker R, Smith A, Shepherd J. The provision of oral surgery services in England and Wales 1984-1991. Br Dent J 1994; 176: 215-219.

23 White D A, Laird W R L, Barclay C W. Patterns of implant referral using a Geographical Information System (GIS). Proceedings of the British Society for the Study of Prosthetic Dentistry, April 2000.

24 Gardner K, Chapple A. Barriers to referral in patients with angina: qualitative study. $\mathrm{Br} \mathrm{Med}$ J 1999; 319: 418-421.

25 Gilthorpe M S, Bedi R. An exploratory study combining hospital episode statistics with socio-demographic variables, to examine the access and utilisation of hospital oral surgery services. Community Dent Health 1997; 14: 209-213. 